NASA Technical Memorandum 106865

AIAA-95-0732

Bagerwh cominims

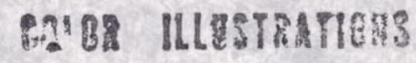

\title{
Crossflow Mixing of Noncircular Jets
}

D.S. Liscinsky and B. True

United Technologies Research Center

East Hartford, Connecticut

J.D. Holdeman

Lewis Research Center

Cleveland, Ohio

Prepared for the

33rd Aerospace Sciences Meeting and Exhibit

sponsored by the American Institute of Aeronautics and Astronautics

Reno, Nevada, January 9-12, 1995

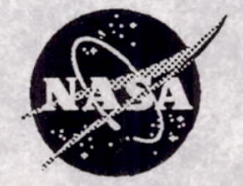

National Aeronautics and Space Administration

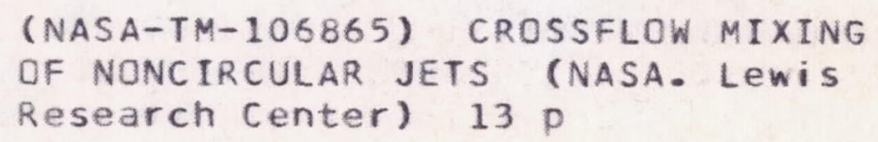

N95-24390

Unclas 


\title{
Crossflow Mixing of Noncircular Jets
}

\author{
D.S. Liscinsky* and B. True ${ }^{* *}$ \\ United Technologies Research Center \\ East Hartford, CT 06108 \\ J.D. Holdeman ${ }^{\dagger}$ \\ NASA Lewis Research Center \\ Cleveland, $\mathrm{OH} 44135$
}

\begin{abstract}
An experimental investigation has been conducted of the isothermal mixing of a turbulent jet injected perpendicular to auniform crossflow through several different types of sharpedged orifices. Jet penetration and mixing was studied using planar Mie scattering to measure time-averaged mixture fraction distributions of circular, square, elliptical, and rectangular orifices of equal geometric area injected into a constant velocity crossflow. Hot-wire anemometry was also used to measure streamwise turbulence intensity distributions at several downstream planes. Mixing effectiveness was determined using (1) a spatial unmixedness parameter based on the variance of the mean jet concentration distributions and (2) by direct comparison of the planar distributions of concentration and of turbulence intensity. No significant difference in mixing performance was observed for the six configurations based on comparison of the mean properties.
\end{abstract}

\section{Nomenclature}

$\alpha \quad$ angle between longest dimension of orifice and axial direction

$\mathrm{A}_{\mathrm{j}} \quad$ orifice area

$\mathrm{A}_{\mathrm{m}}$ cross-sectional area of mainstream duct at injection location

$\mathrm{AR}$ orifice aspect ratio $=\mathrm{L} / \mathrm{W}$

d orifice diameter

$\mathrm{C}_{\text {avg }} \quad\left(\mathrm{mj} / \mathrm{m}_{\mathrm{m}}\right) /\left(1+\mathrm{m}_{\mathrm{j}} / \mathrm{m}_{\mathrm{m}}\right)$

$C_{d} \quad$ orifice discharge coefficient

J jet-to-mainstream momentum-flux ratio $=\left(\rho_{\mathrm{j}} \mathrm{V}_{\mathrm{j}}^{2}\right) /\left(\rho_{\mathrm{m}} \mathrm{U}_{\text {main }}{ }^{2}\right)$

$\mathrm{L} \quad$ long dimension of orifice

$\mathrm{m}_{\mathrm{j}} \quad$ mass flow of the jet

$\mathrm{m}_{\mathrm{m}} \quad$ mass flow of the mainstream

$\rho_{j} \quad$ density of the jet

$\rho_{\mathrm{m}} \quad$ density of the mainstream

$\mathrm{U}_{\mathrm{s}} \quad$ spatial unmixedness parameter (see Eq. 2)

$\begin{array}{ll}\mathrm{V}_{\mathrm{j}} & \text { jet velocity }=\mathrm{m}_{\mathrm{j}} /\left(\rho_{\mathrm{j}} \mathrm{A}_{\mathrm{j}} \mathrm{C}_{\mathrm{d}}\right) \\ \mathrm{U}_{\text {main }} & \text { mainstream velocity } \\ \mathrm{W} & \text { short dimension of orifice } \\ \mathrm{x} & \begin{array}{l}\text { downstream coordinate, } \mathrm{x}=0 \text { at the leading } \\ \text { edge of the orifice }\end{array} \\ \mathrm{y} & \begin{array}{l}\text { cross-stream coordinate (horizontal) } \\ \mathrm{z}\end{array} \\ \text { cross-stream coordinate (vertical) }\end{array}$

\section{Introduction}

Crossflow mixing is employed in many applications. Generally the objective is to rapidly obtain a homogeneous mixture of the injectant and mainstream. The degree and rate of the mixing process is especially important in combustion applications since burning efficiency and exhaust composition directly depend on mass transfer and reaction kinetics. Whereas kinetics are difficult to control, the mixing process is easily affected by any number of parameters and optimization of that process for combustor design has been the topic of several recent investigations ${ }^{1-19}$.

The use of orifice shape to passively control the mixing process has been studied in non-reacting and reacting systems, and the ability of noncircular, low aspect ratio orifices to augment mixing rates in these systems has been demonstrated $^{20-24}$. The increased mixing rate is attributed to generation of "scales" which are smaller than those created by round/ circular shapes. The result is increased mixing on a molecular scale which increases reaction rate. Most previous studies of noncircular orifices use nozzles to generate inlet boundary conditions with components of axial vorticity. The jet then exhausts into a quiescent surrounding. The present investigation is concerned with injection into a crossflow for use in gas turbine combustors where multijet arrangements would be used for modification of the mainstream.

* Research Scientist, Member AIAA

** Senior Laboratory Technician

$\dagger$ Senior Research Engineer, Associate Fellow AIAA 


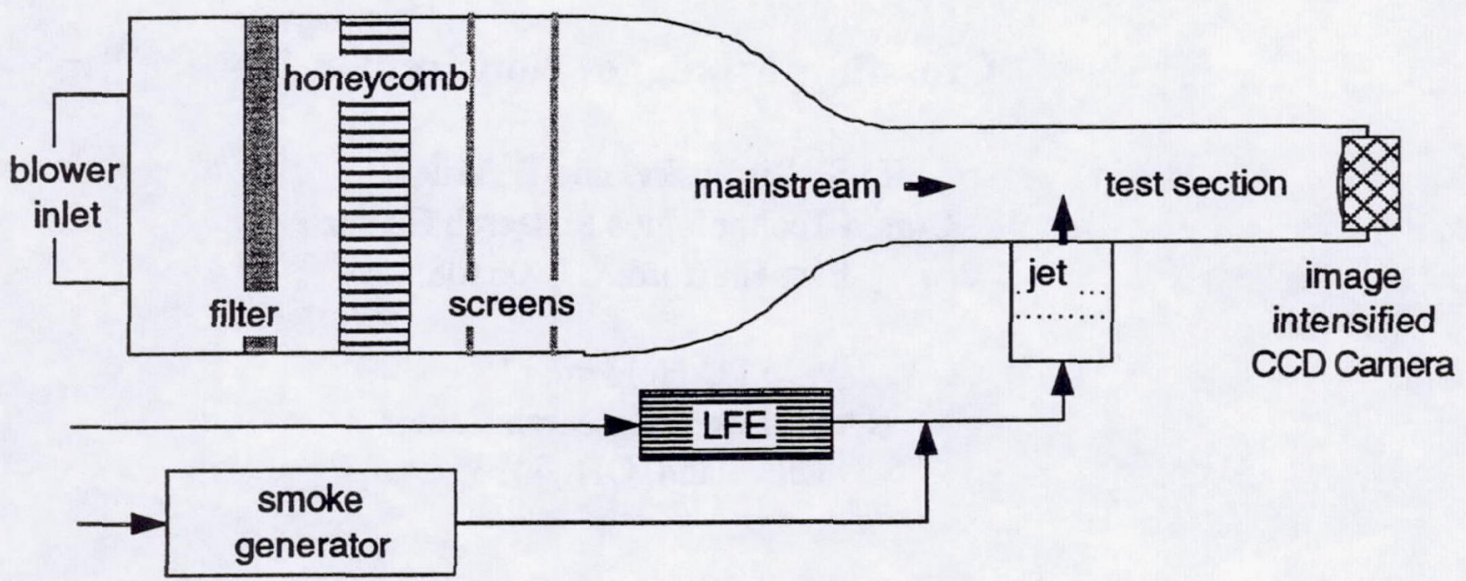

Figure 1: Experimental Configuration used to Measure Planar Concentration Distributions

\section{Experimental}

The mixing experiments were performed in a $5^{\prime \prime} \times 5^{\prime \prime}$ horizontal windtunnel with provision for jet injection through one wall as shown in fig. 1. The air for the crossflow was supplied by a blower attached to the tunnel inlet with an 8 " diameter flexible duct. The inlet/settling section was $17 " \times 17$ " and contained a dense "furnace" filter to distribute the flow, followed by a honeycomb and a series of 2 wire-mesh $50 \%$ open screens for flow conditioning. The $17^{\prime \prime} \times 17^{\prime \prime}$ cross section then contracted on all four sides by a $3^{\text {rd }}$ order polynomial to the $5^{\prime \prime} \times 5^{\prime \prime}$ test section. The crossflow/mainstream velocity was set at $21.8 \mathrm{ft} / \mathrm{s}$ and velocity variation across the test section was less than $5 \%$. Turbulence intensity was $1 \%$.

The jetenters the tunnel through a sharp-edged $(0.125$ " thick) orifice machined into an interchangeable bottom wall. The other three walls of the test section are $0.125^{\prime \prime}$ thick plate glass. The jet flow originates in a 4" $\times 4$ " $\times 5$ " plenum attached to the bottom of the test section. The mass flow into the plenum was maintained at $0.0096 \mathrm{lbm} / \mathrm{s}$ using a laminar flow element.

Table 1 identifies the 6 orifice configurations that were tested. Note that configuration $C \& D$ and $E \& F$ are the same orifice shape rotated $90 \mathrm{deg}$. The physical area of each orifice was $0.44 \mathrm{in}^{2}$. Discharge coefficients $\left(C_{d}\right)$ were measured in a separate apparatus for each orifice plate at the mass flow rate used in the investigation. The $C_{d}$ of each plate was found to be 0.67 resulting in a bulk jet velocity of $62.5 \mathrm{ft} / \mathrm{s}$. The jet-to-mainstream momentum-flux ratio (J) was therefore 8.2. This J was chosen so that the jets would have a trajectory that roughly followed the midpoint of the tunnel and avoid wall contact. The Reynolds number of the jet was typically 24000 .

Mie scattering was the primary diagnostic used to optically measure jet mixture fraction distributions in planes parallel and perpendicular to the duct axis. The planar digital imaging technique (see Ref. 12) is applied by marking the jet flow with an oil aerosol ( $\mu \mathrm{m}$ sized particles). A light sheet ( 0.02 inch thick) is created using a $2 \mathrm{~W}$ argon-ion laser and a rotating mirror. The flow field was illuminated to acquire planes oriented in either: (1) a side view, by passing the light sheet through the orifice centerline in the axial direction, or (2) the end-on view, by passing the light sheet through planes perpendicular to the injection wall ( $y-z$ plane) at various axial locations. An image intensified thermo-electrically cooled CCD camera fitted with standard $35 \mathrm{~mm}$ lenses was used to record the scattered light intensity. For the side views the

\begin{tabular}{|c|c|c|c|c|}
\hline Configuration & $\begin{array}{l}\text { Orifice } \\
\text { Shape }\end{array}$ & Width $\mathrm{x}$ Length & $\begin{array}{l}\text { Aspect Ratio } \\
\text { (AR) }\end{array}$ & $\begin{array}{l}\text { Angle } \\
(\alpha)\end{array}$ \\
\hline A & & $0.75 \times 0.75$ & $1: 1$ & 0 \\
\hline B & & $0.66 \times 0.66$ & $1: 1$ & 0 \\
\hline $\mathrm{C}$ & & $0.53 \times 1.06$ & $2: 1$ & 0 \\
\hline D & & $1.06 \times 0.53$ & $2: 1$ & 90 \\
\hline $\mathrm{E}$ & & $0.49 \times 0.99$ & $2: 1$ & 0 \\
\hline F & & $0.99 \times 0.49$ & $2: 1$ & 90 \\
\hline
\end{tabular}

Table 1: Sharp-edge Orifice Configurations 
camera was focussed through the side window on the illuminated plane. For the end-on view the camera was located inside the duct $2 \mathrm{ft}$ downstream of the orifice midpoint. The camera was programmed to make exposures coincident with the sweep of the beam through the flow field. The mean concentration distributions were acquired over 15 seconds and represent the time-average intensity of about 2000 instantaneous distributions which were then digitized in a $380 \times 380$ pixel format (pixel size $=0.013^{\prime \prime} \times 0.013^{\prime \prime} \times 0.015^{\prime \prime}$ ) and sent to a computer for storage. The scattered light intensity is proportional to the number of particles in the measurement volume. If only one of two streams is marked (in this study the jet fluid), the light intensity of the undiluted marked fluid represents mole fraction unity.

In addition to the optical measurements, a series of gas sampling probe measurements were made to provide independent calibration of the Mie scattering distributions. A methane tracer was introduced into the jet fluid and a total hydrocarbon analyzer was used to detect the methane. For those measurements a $0.125^{\prime}$ diameter stainless steel probe was mounted on a platform that could be moved both vertically and horizontally. While the downstream location ( $\mathrm{x}$-direction) was positioned manually, a stepper motor moved the probe in $0.125^{\prime \prime}$ increments throughout the $\mathrm{y}-\mathrm{z}$ plane under computer control. A delay of 2 seconds at each station was sufficient to purge the sample line. The on-line total hydrocarbon analyzer continuously measured the methane concentration which was compared with the reference concentration to obtain jet mixture fraction at 1369 data points.

Mean flow velocity in the streamwise direction and the rms value were obtained using a linearized constant temperature hot-wire anemometer. A single wire oriented perpendicular to the mainstream flow was traversed in a fashion similar to the gas sampling probe described in the previous paragraph. Average quantities were recorded at 440 points/ plane and turbulence intensity is reported. The probe orientation was not varied, therefore only velocity components in the streamwise direction were measured. Although the probe response was $13 \mathrm{kHz}$, spectra were not recorded.

\section{Results and Discussion}

Mean concentration distributions for the six orifice configurations are shown in Fig. 2 (next page). The distributions are side views, the $\mathrm{x}-\mathrm{z}$ plane bisecting the orifice and parallel to the mainstream flow direction. A 10-level color scale is used to represent contours of jet mass fraction from 0 to 1.0 (pure mainstream fluid colored red $=0$ and pure jet fluid colored dark blue $=1.0$, note that the acquired data has a resolution several orders of magnitude greater than that displayed by the contour plot). Mainstream flow is from left-toright and the jet obviously enters from the bottom left. A plan view of the orifice shape is displayed in the upper left corner. The images are cropped so that the left side begins at $x=0$, the leading edge of the orifce, and the right side is at $x / d=5.5$ (where $d=$ the diameter of an equivalent area circle).

The white line through each figure, which starts at the orifice midpoint and bends with the jet, is the same in each of the six plots. It corresponds to the trajectory of the round orifice, i.e. configuration A. Trajectory is defined as the line that intersects the maximum jet concentration as a function of downstream distance. The black line plotted on the round orifice data (configuration A) is the trajectory predicted by an empirical correlation reported by Holdeman ${ }^{26}$ for the centerplane temperature trajectory of a single heated jet in crossflow:

$$
\mathrm{z} / \mathrm{d}=0.76\left(\rho_{\mathrm{j}} / \rho_{\mathrm{m}}\right)^{0.15} \mathrm{~J} 0.52(\mathrm{x} / \mathrm{d})^{0.27}
$$

The observed trajectory bends more quickly than the prediction, but overall the agreement is good. All of the configurations except $\mathrm{C}$ and $\mathrm{E}$ are quite similar in trajectory and overall flow features. Configurations $\mathrm{C}$ and $\mathrm{E}$ are slightly different in trajectory and in the wake region directly behind the jet. These configurations have slower mass addition due to their longer axial length. If the origin of the trajectory curve was moved nearer to the leading edge, instead of at the orifice midpoint, the same trajectory curve would closely approximate all of the configurations.

In order to study mixing performance, end-on views (planar cross sections of the flowfield perpendicular to the mainstream flow direction) were acquired at several downstream locations for each orifice configuration. A series of jet mixture fraction distributions obtained by Mie-scattering are displayed for the circular orifice (configuration A) as a function of downstream position in Fig. 3. Again a 10 color contour plot is used to represent jet mixture fraction. Pure mainstream fluid outside of the region of jet/mainstream interaction is not plotted (it would be all red) to highlight the mixing region. The box surrounding the distributions represent the duct which confines the jet. From this view the development of a pair of counterrotating vortices, characteristic of a jet in crossflow, are observed. Spreading of the jet and a decrease in the maximum concentration are also indicated.

In fig. 4 jet mixture fraction distributions of the configurations shown in Table 1 are compared at 4 downstream positions. The downstream position is indicated on the figure as a non-dimensionalized distance where the axial distance is normalized by the orifice diameter $(x / d)$. For the non-circular orifices the equivalent round orifice diameter is used for normalization. In these plots again only the jet/ mainstream mixing region is shown. The primary difference between the distributions is the rate of development of the counterrotating vortices. The development is the most rapid in 


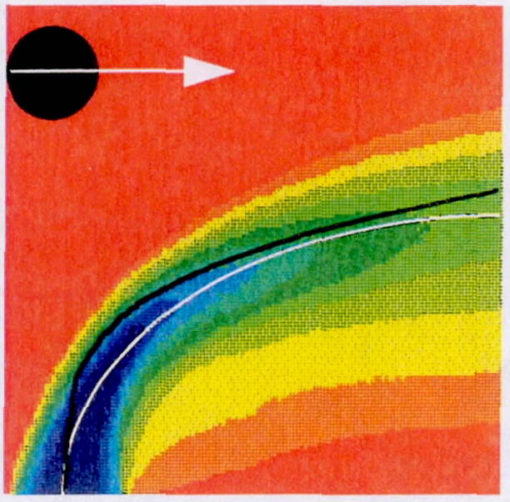

Config. A: Round

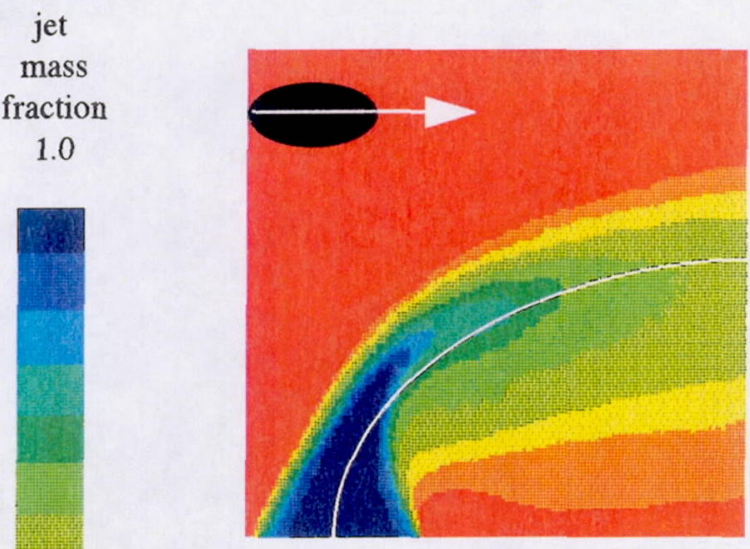

Config. C: Ellipse Aligned

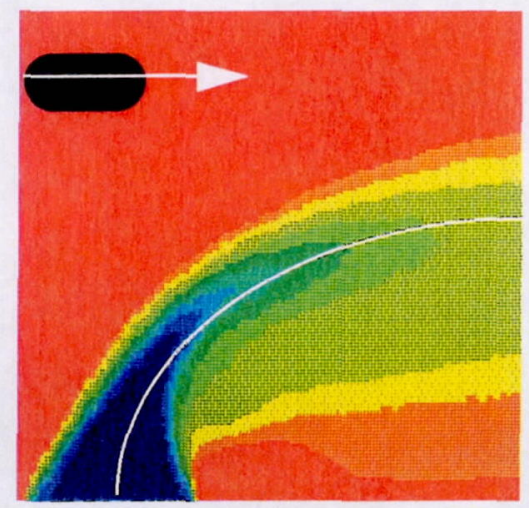

Config. E: Slot Aligned

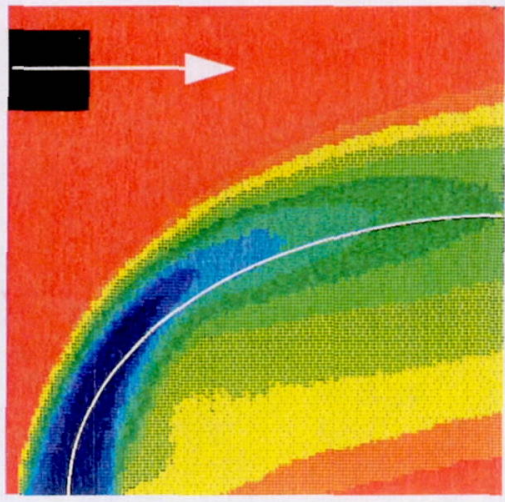

Config. B: Square

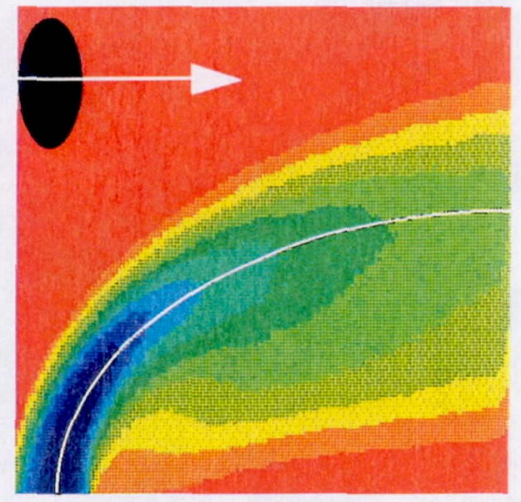

Config. D: Ellipse Transverse

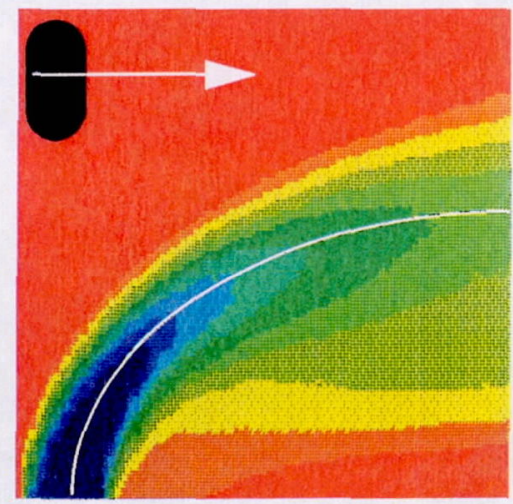

Config. F: Slot Transverse

Figure 2: Side View of the Average Jet Mixture Fraction Distribution for the Six Orifice Configurations in Table 1

(left side of each figure is $x / d=0$, right side is $x / d=5.5$, where $d$ is the diameter of an equivalent area circle) 


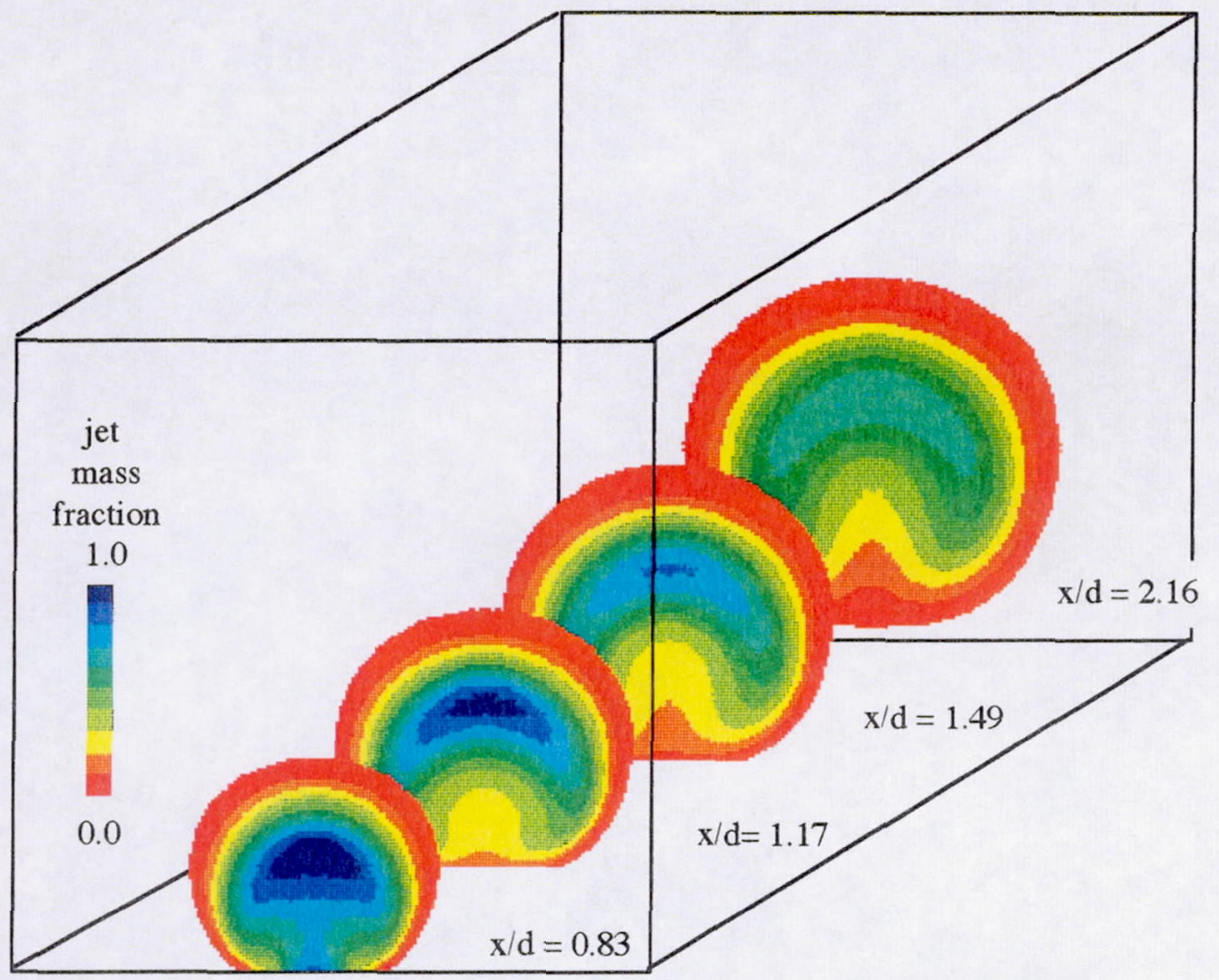

Figure 3: End-on View of the Average Concentration Distribution Downstream of a Round Orifice

configurations $\mathrm{C}$ and $\mathrm{E}$, the aligned ellipse and aligned slot, followed by the circle, square, and transvers ellipse and slot. It is surprising that al though the development of vorticity appear to be quite different, the overall degree of mainstream entrainment, i.e. mixing performance, appears to be similar in each case. Apparently al though low mainstream blockageincreases the degree of counterrotating vorticity, the slower mass addition rate is offsetting. Therefore the net entrainment as a function of downstream distance is equivalent.

The results of the methane tracer analysis are shown in fig. 5 for the first 4 orifice configurations. The plotting is the same as in fig. 4 . Note the spatial resolution is very coarse, but the overall qualities of the flowfield are still apparent. In general the agreement of the two data sets is very good. The ordering of development of vorticity is shown to be the same and the net mixing performance is seen to be quite similar.

In a two-stream mixing problem the fully mixed concentration is defined by the jet-to-mainstream mass flow ratio. A measure of the mixing rate can be obtained by comparing the jet mixture fraction distribution at any downstream plane to the fully mixed value. In ref. 11 the authors developed a measure of unmixedness based on the variance of the concentration distribution, defined as spatial unmixedness:

$$
\mathrm{U}_{\mathrm{s}}=\frac{\mathrm{c}_{\mathrm{var}}}{\mathrm{c}_{\mathrm{avg}}\left(1-\mathrm{c}_{\mathrm{avg}}\right)}
$$

where,

$\mathrm{c}_{\mathrm{var}}=\frac{1}{\mathrm{~m}} \sum_{\mathrm{i}=1}^{\mathrm{m}}\left(\overline{\mathrm{c}_{\mathrm{i}}}-\mathrm{c}_{\mathrm{avg}}\right)^{2}$

$=$ spatial concentration variance

$\overline{c_{i}}=$ time-average concentration at a pixel

$\mathrm{c}_{\mathrm{avg}}=$ fully mixed concentration

$\mathrm{U}_{\mathrm{S}}=0$ corresponds to a perfectly mixed system, and $\mathrm{U}_{\mathrm{S}}=1$ a perfectly segregated system. The denominator is the maximum concentration fluctuation that can occur at the specified fully mixed concentration. Normalizing by this factor allows $U_{s}$ values to be compared regardless of the jet to mainstream mass flow ratio of the system. Therefore, this parameter allows comparison of the relative mixing effectiveness of each configuration reported herein and comparison to other configurations with different mass flow ratios, where $\mathrm{d}=$ the diameter of an equivalent area circle i.e. multijet arrangements. 


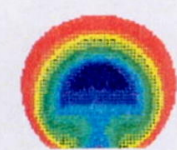

$\mathrm{x} / \mathrm{d}=0.83$

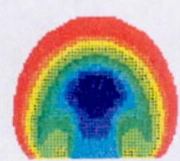

$\mathrm{x} / \mathrm{d}=0.77$
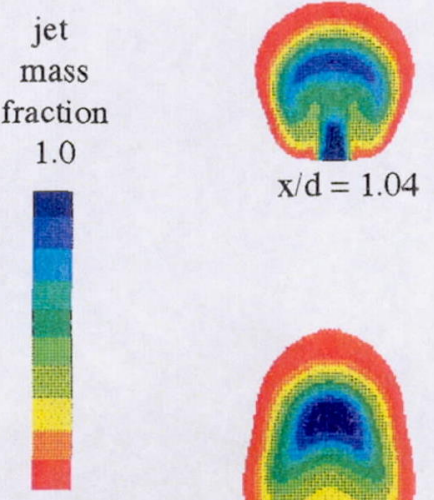

0.0

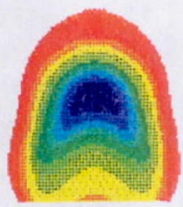

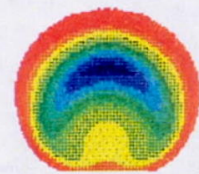

1.17

Configuration $\mathrm{A}$ : round

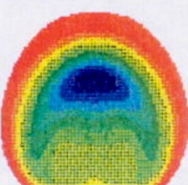

1.11

Configuration B: square

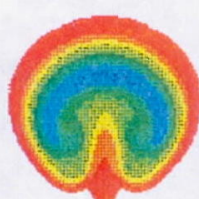

1.37

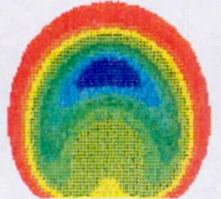

1.44

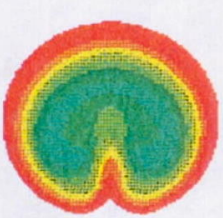

1.71

Configuration $\mathrm{C}$ : ellipse aligned

$\mathrm{x} / \mathrm{d}=1.02$

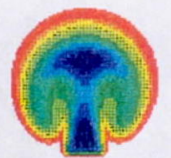

$\mathrm{x} / \mathrm{d}=0.9$

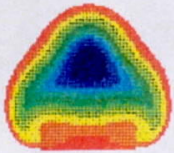

$\mathrm{x} / \mathrm{d}=0.66$

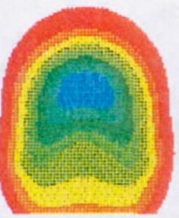

1.35

Configuration D: ellipse transverse

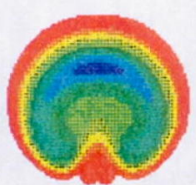

1.33

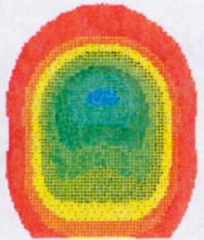

1.69

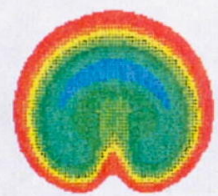

1.66

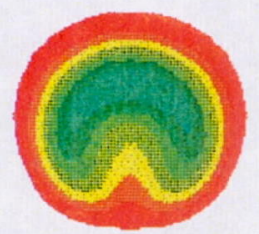

2.16

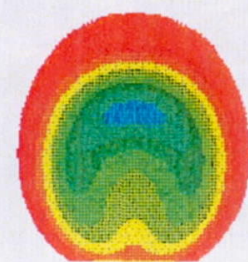

2.11

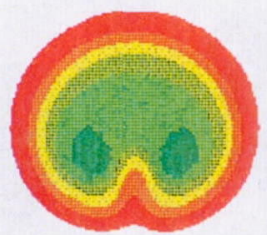

2.37

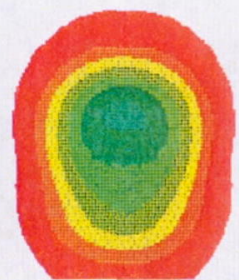

2.02

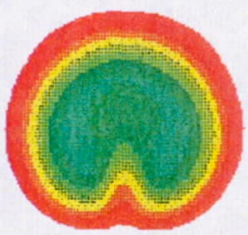

2.33

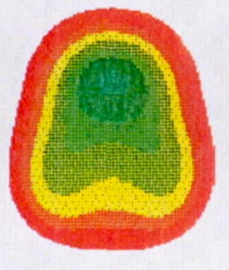

1.99

Configuration F: slot transverse

Figure 4: Comparison of End-on Jet Mixture Fraction Distributions (axial locations are non-dimensionalized by $d$, the equivalent round orifice diameter) 


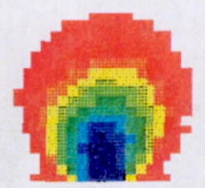

$\mathrm{x} / \mathrm{d}=0.50$

jet
mass

fraction

1.0

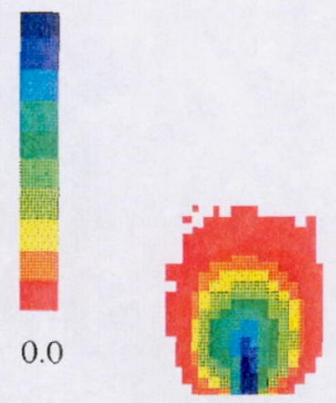

$\mathrm{x} / \mathrm{d}=0.71$

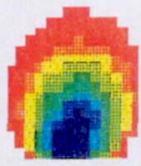

$\mathrm{x} / \mathrm{d}=0.35$

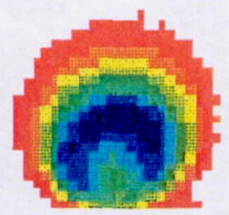

1.0

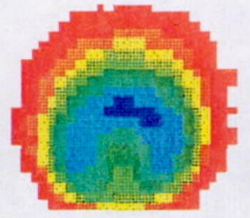

1.33

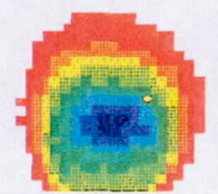

0.88

Configuration B: square

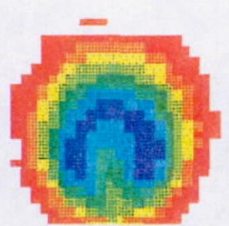

1.41

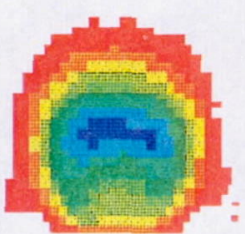

1.33

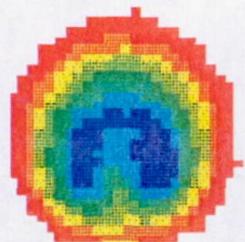

1.33

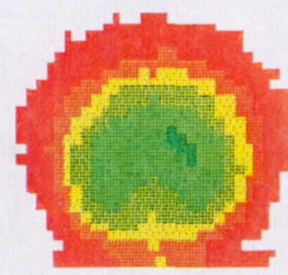

2.67

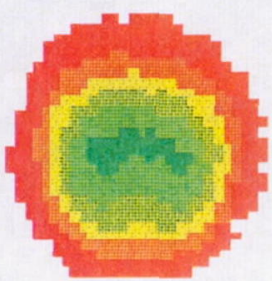

2.67

Configuration $\mathrm{C}$ : ellipse aligned

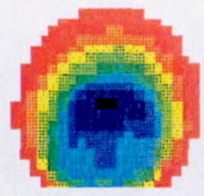

0.71

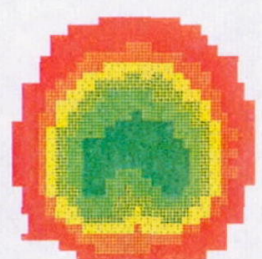

2.67

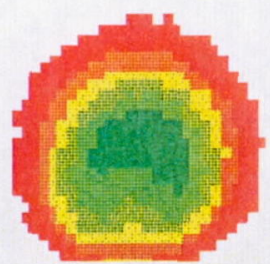

2.67

Configuration $\mathrm{D}$ : ellipse transverse

Figure 5: Comparison of Jet Mixture Fraction Distributions (gas sampling) (axial locations are non-dimensionalized by $\mathrm{d}$, the equivalent round orifice diameter) 
Spatial unmixedness as a function of downstream position for the configurations in Table 1 are shown in figs. $6 \mathrm{a}$ and $6 \mathrm{~b}$. These curves agree with the conclusions reached by comparison of the distributions shown in figs. 4 and 5. Although the mixing rates are slightly different, they are not substantially different.

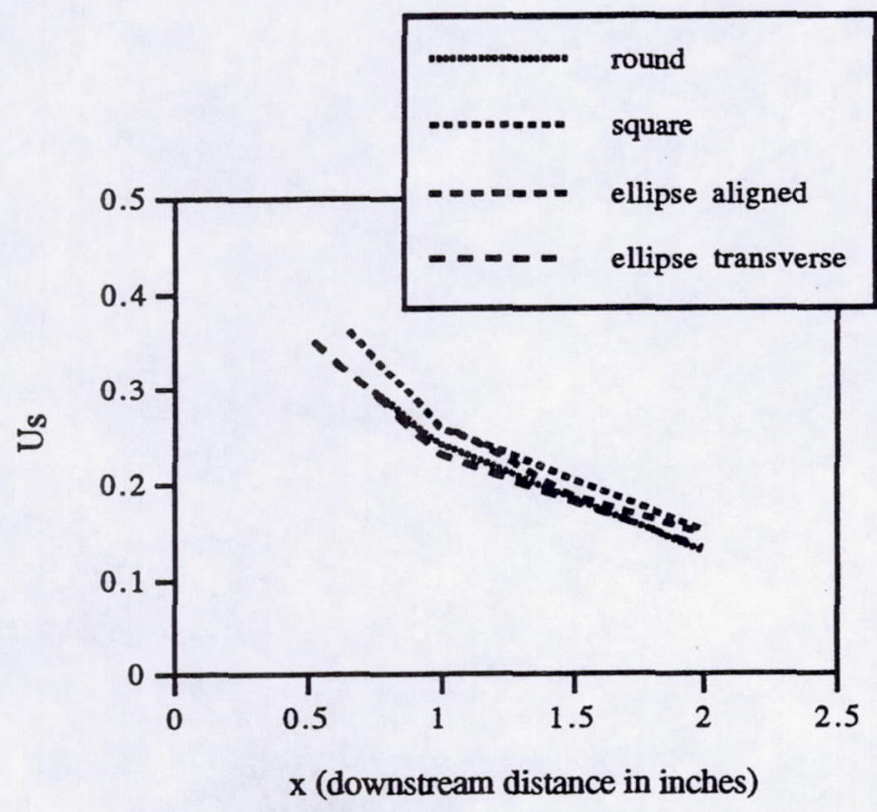

Figure 6a: Comparison of the Spatial Unmixedness of Circular and Noncircular Orifices (configurations A - D)

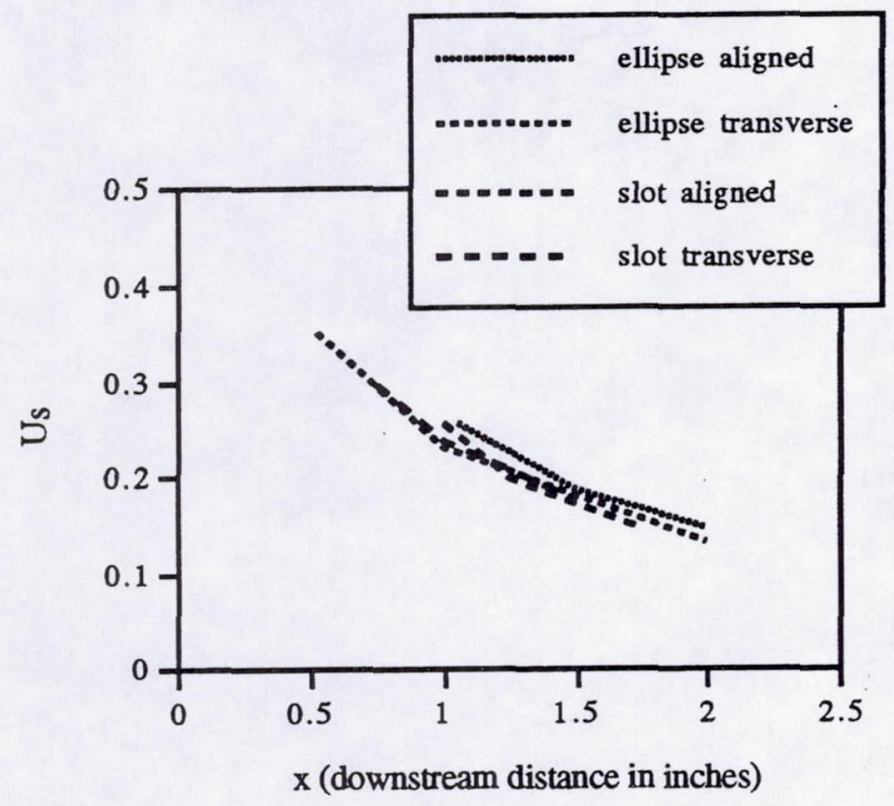

Figure 6b: Comparison of the Spatial Unmixedness of Elliptical and Slot Orifices (configurations C - F)
To further characterize the flowfield and investigate the fluctuating properties, a hot-wire anemometer was used to measure the turbulence intensity in the streamwise direction at several downstream planes for all of the configurations in Table 1. Turbulence intensity is defined as the rms velocity/ mean velocity. In fig. 7 the results are presented as contour plots where red represents the highest fluctuations $(60 \%)$ and black the lowest. The figures represent $2.5^{\prime \prime} \times 2.5^{\prime \prime}$ areas centered around the orifice with the bottom of the figure starting at the injection plane $(\mathrm{z}=0)$.

At the first downstream station, which is a plane through the midpoint of the orifice, the highest levels, which are about $20 \%$, are at the interface of the jet and mainstream. Fluctuations in the core regions directly above the jet are low. The levels and distributions are independent of the configuration. At the trailing edge very high levels are indicated in the wake region for each configuration. Since only a single velocity component was resolved, these measurements are probably biased by intermittency and recirculation in that region. Farther downstream at the $1 "$ and 2 "locations the distributions become symmetric about the orifice midpoint and the highest flucuations are now centered in the plume of the jet. It is surprising that the overall agreement between the configurations is so similar. This would indicate that on average each of the configuration generates similar vorticity in the streamwise direction. The result is consistent with the similarity in entrainment rates indicated by the concentration distributions.

\section{Conclusions}

- Based on themean concentration distributions, turbulent mixing was not affected significantly by orifice shape.

- Mean concentration trajectories are similar independent of orifice shape.

- Concentration distributions are similar whether measured by Mie scattering or by probes.

- Measurements of turbulence intensity indicated that the distribution and level of fluctuation was similar for each shape.

- More detailed analysis using multicomponent hot-wires to resolve the 3D flowfield are necessary to determine the effect of orifice shape on turbulence length scales. Spectra and cross correlations are necessary. 

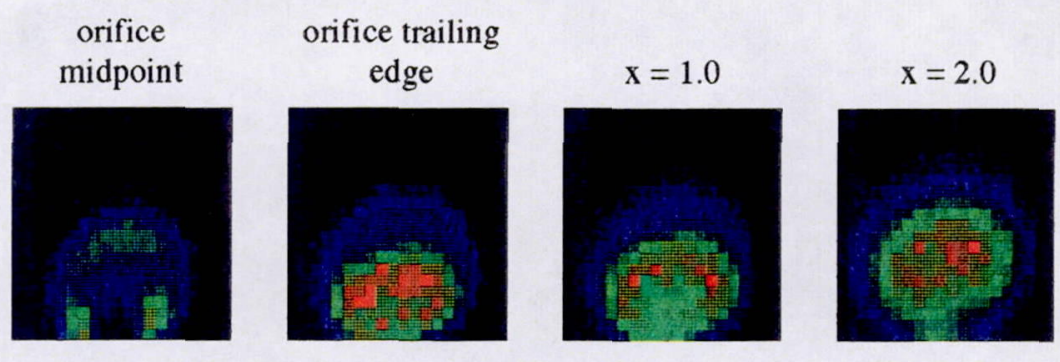

configuration $\mathrm{A}$ : round
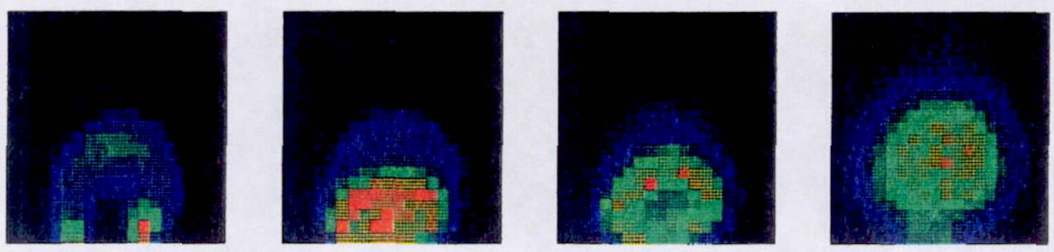

configuration $\mathrm{B}$ : square

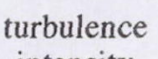
intensity
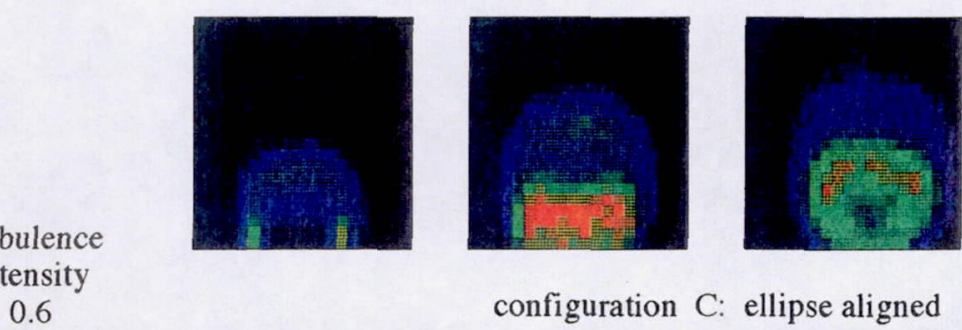

configuration $\mathrm{C}$ : ellipse aligned
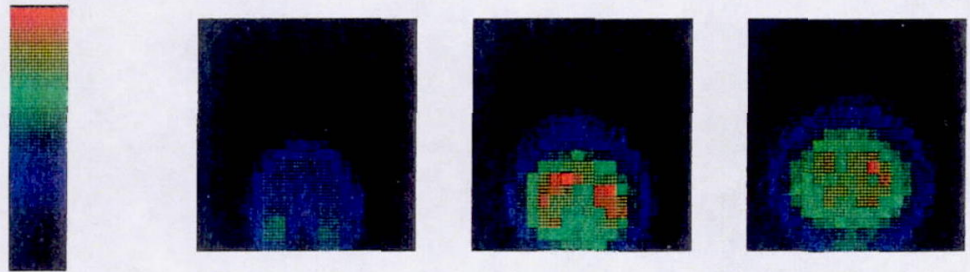

0.0

configuration $\mathrm{D}$ : ellipse transverse
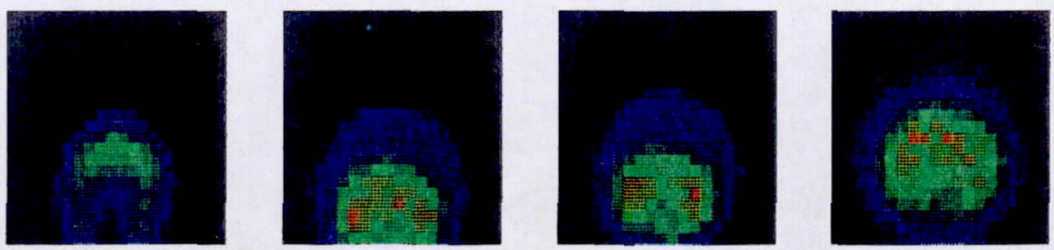

configuration E: slot aligned
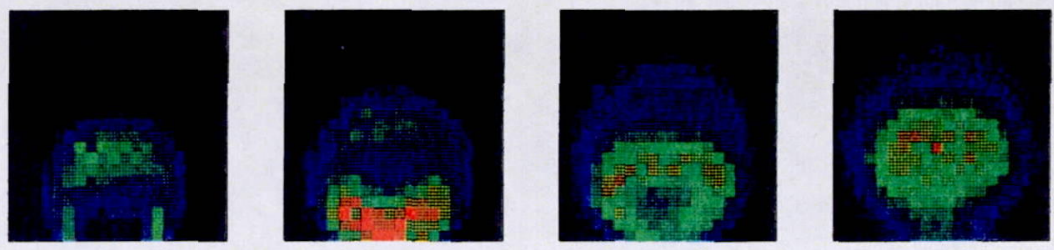

configuration $\mathrm{F}$ : slot transverse

Figure 7: Turbulence Intensity Distributions for the Six Orifice Configurations in Table 1

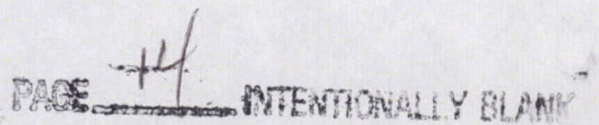


1. Bain, D.B., Smith, C.E., and Holdeman, J.D., "CFD Assessment of Orifice Aspect Ratio and Mass Flow Ratio on Jet Mixing in Rectangular Ducts," AIAA 94-0218, (also NASA TM 106434), Jan. 1994.

2. Bain, D.B., Smith, C.E., and Holdeman, J.D., "CFD Mixing Analysis of Axially Opposed Rows of Jets Injected into a Confined Crossflow," AIAA 93-2044, (also NASA TM 106179), June 1993.

3. Bain, D.B., Smith, C.E., and Holdeman, J.D., "CFD Mixing Analysis of Jets Injected from Straight and Slanted Slots into Confined Crossflow in Rectangular Ducts," AIAA 92-3087, (also NASA TM 105699), July 1992.

4. Doerr, Th. and Hennecke, D.K., "The Mixing Process in the Quenching Zone of the Rich-Lean Combustion Concept," AGARD-PEP 81st Symposium of Fuels and Combustion Technology for Advanced AircraftEngines, 1993.

5. Hatch, M.S., Sowa, W.A., Samuelsen, G.S., and Holdeman, J.D., "Jet Mixing Into a Heated Cross Flow in a Cylindrical Duct: Influence of Geometry and Flow Variations," AIAA 92-0773, (also NASA TM 105390), Jan. 1992.

6. Hatch, M.S., Sowa, W.A., Samuelsen, G.S., and Holdeman, J.D., "Influence of Geometry and Flow Variations on NOFormation in the QuickMixer of a Staged Combustor," NASA TM 105639, July 1992.

7. Holdeman, J.D., "Mixing of Multiple Jets with a Confined Subsonic Crossflow," Prog. Energy Combust. Sci., 19, p31-70, 1993 (also ALAA 91-2458, June 1991 and NASA TM 104412).

8. Howe, G.W., Li, Z., Shih, T.I.-P., and Nguyen, H.L., "Simulation of Mixing in the Quick Quench Region of a Rich Burn - Quick Quench Mix- Lean Burn Combustor," AIAA-91-0410, 1991.

9. Kroll, J.T., Sowa, W.A., Samuelsen, G.S., and Holdeman, J.D., "Optimization of Circular Orifice Jets Mixing into a Heated Crossflow in a Cylindrical Duct," AIAA 93-0249, (also NASA TM 105984), Jan. 11-14, 1993.

10. Liscinsky, D.S., True, B., and Holdeman, J.D., "Mixing Characteristics of Directly Opposed Rows of Jets Injected Normal to a Crossflow in a Rectangular Duct, " AIAA-940217, Jan. 1994.
11. Liscinsky, D.S., True, B., and Holdeman, J.D., "Experimental Investigation of Crossflow Jet Mixing in a RectangularDuct," AIAA 93-2037, (alsoNASA TM 106152), June 1993.

12. Liscinsky, D.S., True, B., Vranos, A., and Holdeman, J.D., "Experimental Study of Cross-Stream Mixing in a Rectangular Duct," AIAA Paper 92-3090, (also NASA TM 106194), July 1992.

13. Oechsle, V.L., Mongia, H.C., and Holdeman, J.D., "Comparison of the Mixing Calculations of the Reacting and Nonreacting Flows in a Cylindrical Duct," AIAA-940865, (also NASA TM 106435), Jan. 1994.

14. Oechsle, V.L., Mongia, H.C., and Holdeman, J.D., "An Analytical Study of Jet Mixing in a Cylindrical Duct," AIAA 93-2043, (also NASA TM 106181), June 1993.

15. Oechsle, V.L., Mongia, H.C., and Holdeman, J.D., "A Parametric Numerical Study of Mixing in a Cylindrical Duct," AIAA 92-3088, (also NASA TM 105695), July 6-8, 1992.

16. Smith, C.E., Talpallikar, M.V., and Holdeman, J.D., "A CFD Study of Jet Mixing in Reduced Areas for Lower Combustor Emissions," AIAA Paper 91-2460, (also NASA TM 104411), June 1991.

17. Sowa, W.A., Kroll, J.T., Samuelsen, G.S., and Holdeman, J.D, "Optimization of Orifice Geometry for CrossFlow Mixing in a Cylindrical Duct," AIAA 94-0219, (also NASA TM 106436), Jan. 1994.

18. Talpallikar, M.V., Smith, C.E., Lai, M.C., and Holdeman, J.D., "CFD Analysis of Jet Mixing in Low NOx Flametube Combustors," J. Eng. Gas Turbine Pwr., 114, 416, 1992, (also ASME 91-217 and NASA TM 104466, 1991).

19. Vranos, A., Liscinsky, D.S., True, B., and Holdeman, J.D., "Experimental Study of Cross-Stream Mixing in a Cylindrical Duct," AIAA 91-2459, (also NASA TM 105180), June 1991.

20. Zhu, G., andLai, M.-C., "A Parametric Study of Penetration and Mixing of Radial Jets in Necked-Down Cylindrical Cross-Flow," AIAA-92-3091, July 1992. 
21. Ho, C.-M, and Gutmark, E., "Vortex Induction and Mass Entrainment in a Small-Aspect-Ratio Elliptic Jet," $J$. Fluid Mech., 179, pp383-405, 1987.

22. Gutmark, E. and Ho, C.-M., "Visualization of a Forced Elliptic Jet, ALAA J., 24, pp. 684-685, 1986.

23. Gutmark, E. and Schadow, K.C., "Flow Characteristics of Orifice and Tapered Jets," Phys. Fluids, 30 (11), pp. 3448-3454, November 1987.

24. Quinn, W.R., "On Mixing in an Elliptic Turbulent Free Jet," Phys. Fluids , A 1 (10), pp. 1716-1722, October 1989.

25. Wu, J.M., Vakili, A.D., and Yu, F.M., "Investigation of the Interacting Flow of Nonsymmetric Jets in Crossflow," AIAA Journal, 26 (8), pp. 940-947, August 1988.

26. Liscinsky, D.S. and True, B. "Planar Mie Scattering Measurements of Scalar Mixing," SPIE Proceedings Vol. 2122-18, Jan. 1994.

27. Holdeman, J.D., "Correlation for Temperature Profiles in the Plane of Symmetry Downstream of a Jet Injected Normal to a Crossflow," NASA TN D-6966 September 1972.

\section{Acknowledgements}

This work was supported by NASA Contract NAS325954, Task Order \#12 The assistance of Brian Knight of UTRC with the hot-wire anemometry is gratefully acknowledged. 


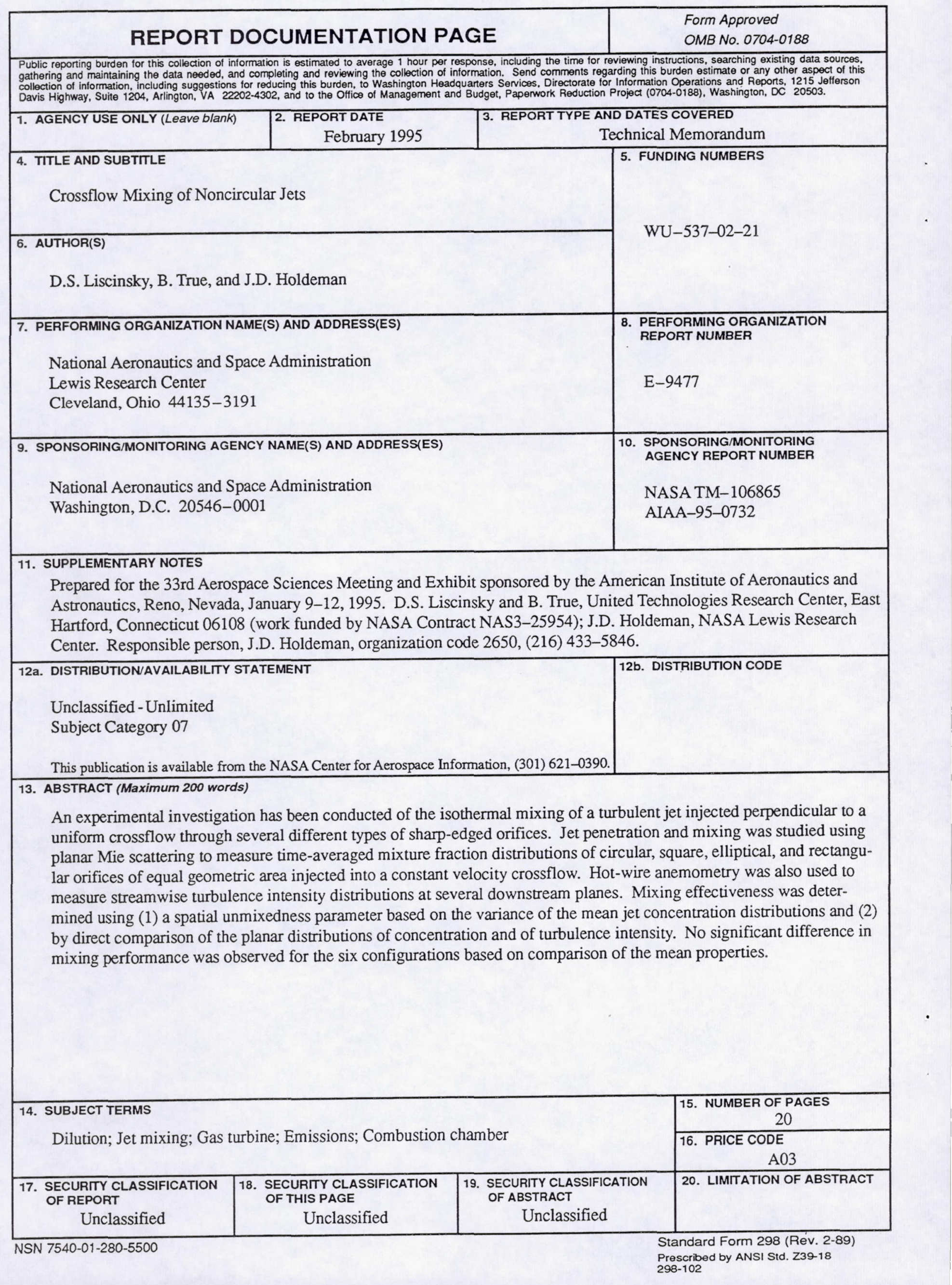

